\title{
Preparation, cytotoxicity, and in vivo antitumor efficacy of "'In-labeled modular nanotransporters
}

\author{
This article was published in the following Dove Press journal: \\ International Journal of Nanomedicine \\ 10 January 2017 \\ Number of times this article has been viewed
}

\author{
Tatiana A Slastnikova',* \\ Andrey A Rosenkranz ${ }^{1,2, *}$ \\ Natalia B Morozova ${ }^{3}$ \\ Maria S Vorontsova ${ }^{3}$ \\ Vasiliy M Petriev 4,5 \\ Tatiana N Lupanova' \\ Alexey $\mathrm{V}$ Ulasov' \\ Michael R Zalutsky ${ }^{6}$ \\ Raisa I Yakubovskaya ${ }^{3}$ \\ Alexander S Sobolev1,2 \\ 'Laboratory of Molecular Genetics \\ of Intracellular Transport, Institute \\ of Gene Biology, Russian Academy \\ of Sciences, ${ }^{2}$ Department of \\ Biophysics, Biological Faculty, \\ Lomonosov Moscow State University, \\ ${ }^{3}$ Department of Anticancer Therapy \\ Modifiers and Protectors, Moscow \\ Hertsen Research Institute of \\ Oncology, Russian Ministry of Health \\ Care, Moscow, ${ }^{4}$ National Medical \\ Research Radiological Center, Russian \\ Ministry of Health Care, Obninsk, \\ Moscow Region, ${ }^{5}$ Department of \\ Nuclear Medicine, National Research \\ Nuclear University MEPhl (Moscow \\ Engineering Physics Institute), \\ Moscow, Russia; ${ }^{6}$ Department of \\ Radiology, Duke University Medical \\ Center, Durham, NC, USA \\ *These authors contributed equally \\ to this work
}

Correspondence: Alexander S Sobolev Laboratory of Molecular Genetics of Intracellular Transport, Institute of Gene Biology, Russian Academy of Sciences, 34/5 Vavilov St, Moscow I 1 9334, Russia

Tel +7499 I 353100

Fax +74991354105

Email alsobolev@yandex.ru
Purpose: Modular nanotransporters (MNTs) are a polyfunctional platform designed to achieve receptor-specific delivery of short-range therapeutics into the cell nucleus by receptormediated endocytosis, endosome escape, and targeted nuclear transport. This study evaluated the potential utility of the MNT platform in tandem with Auger electron emitting ${ }^{111}$ In for cancer therapy.

Methods: Three MNTs developed to target either melanocortin receptor-1 (MC1R), folate receptor (FR), or epidermal growth factor receptor (EGFR) that are overexpressed on cancer cells were modified with p-SCN-Bn-NOTA and then labeled with ${ }^{111}$ In in high specific activity. Cytotoxicity of the ${ }^{111}$ In-labeled MNTs was evaluated on cancer cell lines bearing the appropriate receptor target (FR: HeLa, SK-OV-3; EGFR: A431, U87MG.wtEGFR; and MC1R: B16-F1). In vivo micro-single-photon emission computed tomography/computed tomography imaging and antitumor efficacy studies were performed with intratumoral injection of MC1R-targeted ${ }^{111}$ In-labeled MNT in B16-F1 melanoma tumor-bearing mice.

Results: The three NOTA-MNT conjugates were labeled with a specific activity of $2.7 \mathrm{GBq} / \mathrm{mg}$ with nearly $100 \%$ yield, allowing use without subsequent purification. The cytotoxicity of ${ }^{111} \mathrm{In}$ delivered by these MNTs was greatly enhanced on receptor-expressing cancer cells compared with ${ }^{111}$ In nontargeted control. In mice with B16-F1 tumors, prolonged retention of ${ }^{111}$ In by serial imaging and significant tumor growth delay ( $82 \%$ growth inhibition) were found.

Conclusion: The specific in vitro cytotoxicity, prolonged tumor retention, and therapeutic efficacy of MC1R-targeted ${ }^{111}$ In-NOTA-MNT suggest that this Auger electron emitting conjugate warrants further evaluation as a locally delivered radiotherapeutic, such as for ocular melanoma brachytherapy. Moreover, the high cytotoxicity observed with FR- and EGFRtargeted ${ }^{111}$ In-NOTA-MNT suggests further applications of the MNT delivery strategy should be explored.

Keywords: nuclear delivery, cancer, melanoma, radionuclide therapy, Auger electrons

\section{Introduction}

Targeted subcellular delivery systems have attracted growing attention in development of anticancer drugs. ${ }^{1-3}$ It is especially concerned with the nuclear targeting system ${ }^{4}$ because the majority of anticancer agents act inside the cell nucleus. However, their real in vivo efficacy is little studied in most cases and for many perspective active principles, it depends on both the efficacy of the delivery system and the attachment technique of these active principles to the vehicle. The high cytotoxicity of Auger electrons when localized in close proximity to cellular DNA is an attractive feature for molecularly targeted radiotherapy. ${ }^{5}$ Moreover, their circumscribed tissue range (generally $<0.1 \mu \mathrm{m}$ ) should also be advantageous in those settings where minimizing collateral damage to the normal tissues adjacent to the tumor is critical, such as in the 
treatment of central nervous system malignancies. ${ }^{6}$ Although radiopharmaceuticals labeled with Auger electron emitters have been considered to be promising as anticancer therapeutic agents for several decades and a lot of research has been done in the field, translation from attractive concept to clinical reality has been difficult. ${ }^{7}$ This can mainly be attributed to the flip side of the coin of their subcellular range of action, namely, that methods must be devised to localize the Auger electron emitter specifically to cancer cells within a tumor and in close proximity to the cell nucleus or preferably within the cell nucleus in order to maximize therapeutic effectiveness. A wide variety of approaches have been investigated for achieving this difficult task, including antibodies, ${ }^{8}$ functionalized antibodies, ${ }^{9}$ small molecules, ${ }^{10}$ block copolymer micelles, ${ }^{11}$ and peptides, ${ }^{12}$ with varying degrees of success.

We have been working on an alternative strategy for achieving molecularly directed selective delivery of shortrange therapeutics such as Auger electron emitters to malignant cell populations, based on an engineered polypeptide platform. ${ }^{13}$ These modular nanotransporters (MNTs) are artificial multifunctional molecules designed to facilitate receptor-specific transport from the cell surface into its nucleus through inclusion of polypeptide domains for accomplishing receptor binding and internalization as well as endosomal escape and nuclear translocation. Moreover, MNTs possess interchangeable component domains, permitting relatively facile exchange of receptor recognition domains, which ultimately might be adapted for different diseases or might help improve homogeneity of drug delivery by targeting several tumor-specific molecules for personalized medicine. MNTs reactive with a variety of tumor-associated receptors have shown promise for delivering short range of action therapeutics including photosensitizers, ${ }^{13,14}$ the $\alpha$-emitter ${ }^{211} \mathrm{At},{ }^{15}$ and the Auger electron emitters ${ }^{125} \mathrm{I}^{16}$ and ${ }^{67} \mathrm{Ga},{ }^{17}$ as they were demonstrated to colocalize in the nuclei of target cancer cells in vitro (up to $60 \%$ of internalized found in nuclei) $)^{13,14,16,17}$ and in vivo, ${ }^{14}$ as well as enhance significantly cytotoxicity of all the above-mentioned cargoes in vitro ${ }^{13,15-18}$ and the therapeutic potential of different photosensitizers in vivo. ${ }^{14}$ Moreover, manifold advantage of full-size MNT over MNTs lacking any of the functional domains for delivery of cytotoxic drugs has been demonstrated previously. ${ }^{18}$ Recent efforts in Auger electron-targeted radiotherapy have been primarily focused on applications involving ${ }^{111} \mathrm{In}^{8,9,11,12}$ based, in part, on its ready availability, commercial and clinically compatible 2.8-day half-life, and the wealth of experience in patients with ${ }^{111}$ In-labeled compounds as imaging agents. With regard to its low-energy electron spectrum, ${ }^{111}$ In emits 14.7 Auger and Coster-Kronig electrons per decay; ${ }^{19}$ moving its site of decay from the cell surface to the nucleus would increase the radiation dose delivered to the cell nucleus by more than tenfold for typical cell geometries. ${ }^{20}$ Based on its excellent properties for imaging and Auger electron radiotherapy, ${ }^{111}$ In is an ideal candidate for developing theranostics for use in settings where sparing normal tissue is of paramount importance, such as in the treatment of glioblastoma infiltrating normal brain or in the ocular brachytherapy and prostate brachytherapy.

The objective of the current study was first to adapt ${ }^{111} \mathrm{In}$ polypeptide labeling methodologies for use with MNTs, which have isoelectric points in the optimum $\mathrm{pH}$ range for indium chelation, which complicates this process, and then to evaluate the resultant ${ }^{111}$ In-labeled MNT as targeted radiotherapeutics in cell culture and animal cancer models.

\section{Materials and methods Cell lines}

The mouse melanoma B16-F1 and human epidermoid carcinoma A431 cells were obtained from the American Type Culture Collection (Manassas, VA, USA). Human cervical carcinoma HeLa cells and human ovarian carcinoma SK-OV-3 cells were kindly provided by Prof E Sverdlov and Prof S Deev, respectively, both from the Institute of Bioorganic Chemistry, RAS. The use of HeLa and SK-OV-3 cell lines was approved by Moscow State University Commission on Bioethics. Human glioma U87 cells transfected to express epidermal growth factor receptor (EGFR; U87MG.wtEGFR) were kindly provided by Dr Darell Bigner, Duke University Medical Center. The cells were cultured in Dulbecco's Modified Eagle's Medium (DMEM; B16-F1, A431), Zink Option Improved MEM (U87MG.wtEGFR), or in-house folate-deficient media (HeLa, SK-OV-3) supplemented with both $10 \%$ calf fetal serum and gentamicin $(50 \mathrm{mg} / \mathrm{L})$ at $37^{\circ} \mathrm{C}$ in a $5 \% \mathrm{CO}_{2}$ atmosphere.

\section{Modular nanotransporters}

Three different MNT molecules were used in these experiments (Figure 1): 1) melanocortin-1 receptor targeted tDToxHMP-NLS-MSH (MNT-MSH), $\mathrm{M}_{\mathrm{w}}$ 70,430 Da, consisting of $\alpha$-melanocyte-stimulation hormone (MSH) as the ligand module, the diphtheria toxin translocation domain (tDTox) as an endosomolytic module, the optimized nuclear localization sequence of SV-40 large T-antigen (NLS), and hemoglobinlike protein (HMP) as a carrier module $;{ }^{14}$ 2) epidermal growth factor (EGF) receptor targeted tDTox-HMP-NLS-EGF (MNT-EGF), ${ }^{13,14} \mathrm{M}_{\mathrm{w}}$ 76,306 Da; and 3) folate receptor(FR)targeted MNT, possessing folic acid (FA; Sigma, St Louis, 
A

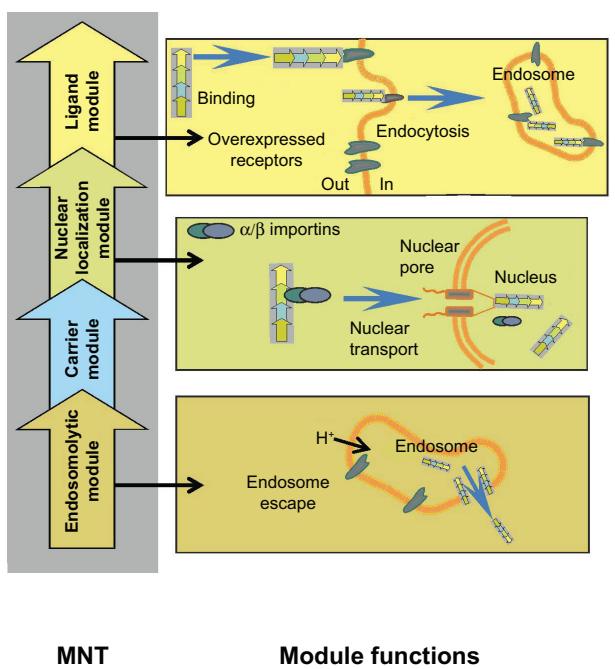

B

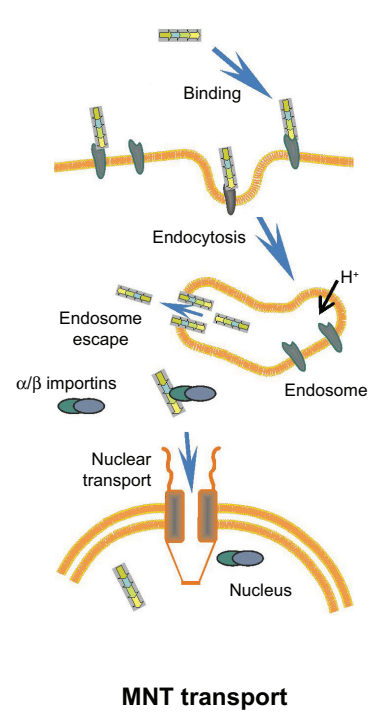

C

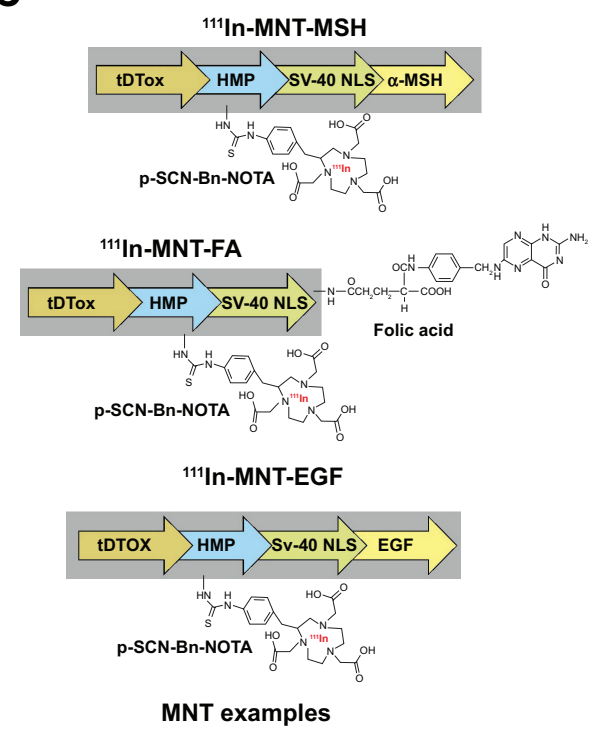

Figure I Schematic presentation of MNTs used in the study.

Notes: (A) Principal scheme of MNT structure and representation of the function of each module. (B) Schematic presentation of MNT transport from the target cell surface to its nucleus. (C) MNTs used in the current study. MNT is designed to recognize and bind through its ligand module to internalizable receptors expressed on the surface of target cells; following subsequent internalization by receptor-mediated endocytosis, the MNT escapes from the endosomes with the help of its endosomolytic module; finally, the MNT binds through its nuclear localization signal module to importins in the hyaloplasm and this complex is transported through the nuclear pore into the target cell nucleus. MSH targeted to melanocortin receptor-I, EGF targeted to EGF receptor, or FA targeted to folate receptors served as different ligand modules; tDTox served as the endosomolytic module, the optimized SV-40 large T-antigen NLS was responsible for importin binding and transport into the nucleus through nuclear pore, and Escherichia coli HMP was used as the carrier module.

Abbreviations: EGF, epidermal growth factor; FA, folic acid; HMP, hemoglobin-like protein; MNTs, modular nanotransporters; MSH, $\alpha$-melanocyte-stimulation hormone; NLS, nuclear localization sequence; P-SCN-Bn-NOTA, chelator S-2-(4-isothiocyanatobenzyl)-I,4,7-triazacyclononane-I,4,7-triacetic acid; tDTox, the diphtheria toxin translocation domain.

MO, USA) covalently attached to the polypeptide tDToxHMP-NLS ( $\left.\mathrm{M}_{\mathrm{w}} 70,125 \mathrm{Da}\right)$ by $N$-hydroxysuccinimide and ethylene dicyclohexyl carbodiimide, as it was described for albumin. ${ }^{21}$ All MNTs were synthesized and purified as described earlier. ${ }^{13,14,18}$ Briefly, each MNT was expressed in an Escherichia coli suspension $\left(\mathrm{OD}_{600} 0.6-1.0\right)$ by the addition of isopropyl- $\beta$-D-1-thiogalactopyranoside to a final concentration of $200 \mu \mathrm{M}$ at $18^{\circ} \mathrm{C}$ and shaking at $170-180 \mathrm{rpm}$ for $2 \mathrm{~h}$. Bacterial cells were pelleted by centrifugation at $10,000 \mathrm{rpm}$ with a JA- 10 rotor at $4^{\circ} \mathrm{C}$ for $30 \mathrm{~min}$. Then, the pellets were frozen for subsequent lysis in ice-cold $50 \mathrm{mM}$ sodium phosphate, $300 \mathrm{mM} \mathrm{NaCl}$, pH 8.0, $1 \mathrm{mM}$ phenylmethylsulfonyl fluoride, $5 \mathrm{mg} / \mathrm{mL}$ lysozyme, and $0.5 \%$ Triton $\mathrm{X}-100$. The obtained lysate was clarified by centrifugation at $18,000 \mathrm{rpm}$ with a JA-20 rotor at $4^{\circ} \mathrm{C}$ for $30 \mathrm{~min}$. Then, the supernatant was loaded onto an Ni-NTA agarose (Qiagen $\mathrm{NV}$, Venlo, the Netherlands) column, washed with $50 \mathrm{mM}$ sodium phosphate, $300 \mathrm{mM} \mathrm{NaCl}, 20 \mathrm{mM}$ imidazole, $\mathrm{pH} 8.0$, $0.5 \%$ Triton $\mathrm{X}-100$, and $1 \%$ glycerol, followed by $50 \mathrm{mM}$ sodium phosphate, $300 \mathrm{mM} \mathrm{NaCl}, 20 \mathrm{mM}$ imidazole, $\mathrm{pH}$ 8.0. MNTs were eluted with $50 \mathrm{mM}$ sodium phosphate, $300 \mathrm{mM}$ $\mathrm{NaCl}, 700 \mathrm{mM}$ imidazole, $\mathrm{pH} 8.0$, and dialyzed against $10 \mathrm{mM}$ sodium phosphate, $150 \mathrm{mM} \mathrm{NaCl}, \mathrm{pH} 7.4$.
The FR-targeted MNT was synthesized by chemical attachment of FA to ligand-free MNT according to the protocol described previously for FA attachment to albumin. ${ }^{21}$ Briefly, FA (Sigma) was dissolved in dimethyl sulfoxide to a concentration of $0.1 \mathrm{M}$ and incubated with an 1.2-fold molar excess of 1-ethyl-3-(3-dimethylaminopropyl)carbodiimide for $1 \mathrm{~h}$ at room temperature (RT), followed by the addition of $N$-hydroxysuccinimide in 1.2-fold molar excess. After $4 \mathrm{~h}$ of incubation at RT, a 15-fold molar excess of the "activated" FA was added to the ligand-free MNT solution and incubated for $12 \mathrm{~h}$ at RT. The unconjugated FA as well as the reaction by-products were removed by five cycles of ultrafiltration with an Amicon Ultra Centrifugal Filter Unit (Ultracel-30K; Merck Millipore Ltd, Tullagreen, Ireland), yielding purified MNT-FA. FA:MNT ratio in the obtained MNT-FA was estimated spectrophotometrically. Purity and integrity of MNT were determined by Laemmli sodium dodecyl sulfate (SDS)-PAGE using Mini-Protean TGX Any kD gels (Bio-Rad Laboratories Inc., Hercules, CA, USA) with subsequent Coomassie Blue staining. The obtained images were analyzed using ImageQuant TL 5.0 software (Bio-Rad Laboratories Inc.). All three MNTs were visualized by atomic force microscopy (Figure S1). 


\section{Conjugation of p-SCN-Bn-NOTA or p-SCN-Bn-DOTA to MNT}

To permit subsequent ${ }^{111}$ In labeling, the chelator $S$-2-(4isothiocyanatobenzyl)-1,4,7-triazacyclononane-1,4,7triacetic acid (p-SCN-Bn-NOTA; Macrocyclics, Dallas, TX, USA; $\left.-\log \mathrm{K}_{\mathrm{In} 3+\mathrm{NOTA}}=26.2\right)^{22}$ or $S$-2-(4-isothiocyanatobenzyl)1,4,7,10-tetraazacyclododecane tetraacetic acid (p-SCN-BnDOTA; Macrocyclics; $\left.-\log \mathrm{K}_{\mathrm{In} 3+\mathrm{DOTA}}=23.9\right)^{22}$ was conjugated to MNT according to a recently published protocol, ${ }^{17}$ using 10-fold chelator molar excess over MNT. All buffers for chelator conjugation and labeling procedures were first passed through a Chelex-100 resin (200-400 mesh, Bio-Rad Laboratories Inc.) to minimize adventitious heavy metal ion contamination. Briefly, 1-16 mg of each MNT was incubated with a 10 -fold molar excess of the chelator in $1 \times \mathrm{pH} 8.6$ conjugation buffer ${ }^{17}$ for $24 \mathrm{~h}$ at $\mathrm{RT}$ with a final concentration of MNT $\geq 1.5 \mathrm{mg} / \mathrm{mL}$. The chelator-MNT conjugate was concentrated and separated from the excess chelator by five cycles of ultrafiltration with an Amicon Ultracel-30K unit. During this process, the conjugation buffer was gradually replaced with $10 \mathrm{mM}$ HEPES, $15 \mathrm{mM} \mathrm{NaCl}, \mathrm{pH}$ 7.4. The chelator-MNT molar ratio was determined by MALDI-MS performed on a MALDI TOF/TOF Mass Spectrometer (Shimadzu, Kyoto, Japan) using a nitrogen laser at $337 \mathrm{~nm}$ with 500 shots per probe. Purity and integrity of chelatorMNT were determined by Laemmli SDS-PAGE using MiniProtean TGX Any kD gels (Bio-Rad Laboratories Inc.) with subsequent Coomassie Blue staining. The obtained images were analyzed using ImageQuant TL 5.0 software (Bio-Rad Laboratories Inc.).

\section{Labeling of chelator-MNT conjugates with "'In}

We searched for optimal conditions for labeling chelator-MNT with ${ }^{111}$ In that would be compatible with the isoelectric points of these MNTs (5.5-5.6, calculated) and would also provide high radiochemical yield and specific activity. Variables included reaction mixture $\mathrm{pH}, \mathrm{SDS}$ and citrate concentrations, temperature, and time. Moreover, this was done with ${ }^{111} \mathrm{InCl}_{3}$ preparations having either relatively low (standard diagnostic agent; $0.22 \mathrm{GBq} / \mathrm{mL}$ ) or high (custom-made; $2.3 \pm 0.2 \mathrm{GBq} / \mathrm{mL}$ ) volumetric activity concentrations. The optimized protocol for MNT labeling that follows was used for subsequent experiments. In a typical procedure, $0.12 \mathrm{mg}$ of chelator-MNT in $10 \mathrm{mM}$ HEPES, $15 \mathrm{mM} \mathrm{NaCl}, \mathrm{pH} 7.5$, was mixed with $29 \mu \mathrm{L}$ of $1 \mathrm{M}$ HEPES, $\mathrm{pH} 7.5,21 \mu \mathrm{L}$ of $0.1 \mathrm{M}$ citrate, $\mathrm{pH} 6.7,8 \mu \mathrm{L}$ of $1 \% \mathrm{SDS}$, and $42 \mu \mathrm{L}$ of $0.25 \mathrm{M} \mathrm{HCl}$ (Ultrapure Grade; EMD Millipore, Billerica, MA, USA). Then, $102 \mu \mathrm{L}$ (322 MBq) of ${ }^{111} \mathrm{InCl}_{3}$ (Federal Center of Nuclear Medicine Projects Design and Development, Moscow, Russia) in $0.048 \mathrm{M} \mathrm{HCl}$ was added. The $\mathrm{pH}$ of the final reaction mixture was 4.5. The reaction mixture was incubated at $37^{\circ} \mathrm{C}$ for $1 \mathrm{~h}$ and then the reaction was stopped by addition of $3 \mu \mathrm{L}$ of $0.05 \mathrm{M}$ ethylenediaminetetraacetic acid (EDTA), $\mathrm{pH} 8.0$, followed by gentle mixing and incubation for $10 \mathrm{~min}$ at $37^{\circ} \mathrm{C}$. Finally, the $\mathrm{pH}$ was adjusted to neutral with $24 \mu \mathrm{L}$ of $1 \mathrm{M} \mathrm{NaOH}$. The specific activity obtained for the three ${ }^{111}$ In-NOTA-MNT types using this protocol was $2.7 \mathrm{GBq} / \mathrm{mg}$. As a control for subsequent in vitro and in vivo studies, ${ }^{11}$ In was treated according to the same procedures except that the chelator-MNT was omitted. Radiochemical yields and ${ }^{111} \mathrm{In}$-chelator-MNT integrity were analyzed by Laemmli SDS-PAGE using Mini-Protean TGX Any kD gels (Bio-Rad Laboratories Inc.) with subsequent detection of radioactivity on a Storm 865 PhosphorImager (GE Healthcare Bio-Sciences AB, Uppsala, Sweden). The obtained images were analyzed using ImageQuant TL 5.0 software (Bio-Rad Laboratories Inc.). We have chosen Laemmli SDSPAGE instead of the usually used instant thin layer chromatography to evaluate the labeling yields, since this method not only provides the data about the percentage of unreacted ${ }^{111} \mathrm{In}$ that migrates immediately before bromophenol blue on the gel, but also demonstrates the integrity of protein molecule after labeling.

\section{Cytotoxicity studies}

B16-F1 (melanocortin receptor-1 [MC1R]-positive) ${ }^{23} \mathrm{HeLa}$ or SK-OV-3 (both FR-positive), ${ }^{24,25}$ and A431 or U87MG. wtEGFR (both EGFR-positive) ${ }^{15}$ cells were seeded in 24-well plates $\left(7 \times 10^{3}\right.$ cells/well for B16-F1 and $2.5 \times 10^{4}$ cells/well for other cell lines). Two days later, the medium was refreshed and dilutions of ${ }^{111} \mathrm{In}$-NOTA-MNT $(0.03-9.5 \mathrm{MBq} / \mathrm{mL})$ or ${ }^{111} \mathrm{In}$-EDTA as a control $(0.3-9.5 \mathrm{MBq} / \mathrm{mL})$ were added. Cells were incubated for $48 \mathrm{~h}$ in a humidified atmosphere at $37^{\circ} \mathrm{C}$ in $5 \% \mathrm{CO}_{2}$. Afterward, the medium containing unbound radioactivity was removed and the cells were washed, trypsinized, harvested, and resuspended in $1 \mathrm{~mL}$ of fresh medium. The cells were seeded for a colony-forming assay in $25 \mathrm{~cm}^{2}$ flasks (2,000 cells per flask for HeLa, SK-OV-3, A431, and U87MG.wtEGFR and 500 cells per flask for B16-F1) in DMEM or DMEM/F12 medium supplemented with $10 \%$ calf fetal serum. Colonies were stained 6-11 days later with $0.3 \%$ Crystal Violet and counted.

\section{Animal studies}

These experiments were performed on 8-9-week-old female C57BL/6J mice (Andreevka, Moscow Region, Russia). 
The animals were maintained under specific pathogen-free conditions with access to mouse chow and water ad libitum. The experimental protocol was approved by the Institute Commission for Animals and was performed in accordance with the National Institutes of Health guide for the care and use of laboratory animals. B16-F1 mouse melanoma tumors were established in mice by subcutaneous injection of $10^{6}$ cells suspended in $100 \mu \mathrm{L}$ DMEM medium into the flank region as described previously. ${ }^{14}$

\section{Single-photon emission computed tomography/computed tomography (SPECT/CT) imaging}

For SPECT/CT imaging, the animals were anesthetized with $0.8 \%-1.8 \%$ isoflurane in air. The mice $(n=4$; mean tumor volume: $88 \pm 19 \mathrm{~mm}^{3}$ ) received intratumoral bolus injections of $7.3 \pm 1.1 \mathrm{MBq}$ of ${ }^{111}$ In-NOTA-MNT-MSH in $45 \mu \mathrm{L}$. Whole body imaging was performed on an U-SPECT-II/CT (MILabs, Utrecht, the Netherlands) scanner, beginning immediately after injection and continuing for $2.5 \mathrm{~h}$ (13×10-min frames) using a $1 \mathrm{~mm}$ diameter pinhole collimator, with subsequent immediate whole-animal CT acquisition. Additional SPECT/CT imaging was performed up to 8 days ( 5 frames $\times 10 \mathrm{~min}$ ). The images were reconstructed using U-SPECT-Rec2.34b software obtained from the manufacturer, followed by co-registration of SPECT images to corresponding CT images. Quantitative analysis of images after three-dimensional reconstruction was performed using PMOD 3.4 software (PMOD Technologies Ltd., Zürich, Switzerland).

\section{Therapy studies}

For therapy studies, B16-F1 mouse melanoma tumorbearing mice $(n=5)$ were i.t. injected with $2.6 \mathrm{MBq} / 1.4 \mu \mathrm{g}$, $5.2 \mathrm{MBq} / 2.9 \mu \mathrm{g}$, or $10.4 \mathrm{MBq} / 5.7 \mu \mathrm{g}$ of either ${ }^{111} \mathrm{In}-\mathrm{NOTA}-$ MNT-MSH, or ${ }^{111}$ In-EDTA or unlabeled NOTA-MNT$\mathrm{MSH}$, or saline in a volume $40 \mu \mathrm{L}$. The efficacy of the treatment was monitored using the tumor growth inhibition index, defined as:

$$
\left(1-\frac{\text { Mean volume of treated tumors }}{\text { Mean volume of control tumors }}\right) \times 100 \% \text {. }
$$

\section{Statistical analysis}

The data were analyzed using GraphPad Prism 5 software (GraphPad Software, Inc., La Jolla, CA, USA). Data on the plots represent the mean values, with bars indicating the standard error of mean of 3-6 repetitive values. The significance of the difference was evaluated using the one-way analysis of variance, the Kruskal-Wallis, or F-test.

\section{Results \\ Modular nanotransporters}

MNT-MSH and MNT-EGF are artificial modular polypeptide nanostructures with the functional properties that have been described earlier which are targeted to MC1R and EGFR. ${ }^{13,16,18,26}$ In this study, we also used the same structure lacking any ligand module to produce MNT with FR targeting. FR-targeted MNT was obtained by covalent attachment of FA to MNT molecule, resulting in FA:MNT molar ratio of 1.6:1 in the final product. The ability of MNT-FA to bind target FR receptors specifically by competition studies with free FA was demonstrated on two different cancer cell lines expressing FR (Figure S2).

\section{Labeling of chelator-MNT conjugates with "'In}

MNTs were successfully conjugated with bifunctional p-SCN-Bn-NOTA or p-SCN-Bn-DOTA chelators, yielding chelator:MNT ratio of 2.5 \pm 0.2 . SDS-PAGE of chelatorMNTs is presented in Figure S3.

Due to the hydrolysis of ${ }^{111}$ In at neutral $\mathrm{pH}$ as well as the increased hydrophobicity of these MNTs at slightly acidic $\mathrm{pH}$, attempts to label the NOTA-MNT or DOTA-MNT conjugates with ${ }^{111}$ In either in the acetate buffer routinely used for ${ }^{111}$ In labeling of proteins ${ }^{27}$ or using a protocol that was successful for ${ }^{67} \mathrm{Ga}$ labeling of NOTA-MNT ${ }^{17}$ were futile. Based on the studies by Brom et $\mathrm{al}^{28}$ and Morfin and Toth, ${ }^{29}$ we used HEPES and citrate; we also added a small amount of SDS (10 times below the critical micelle concentration) to the reaction mixture in an attempt to shield the hydrophobic sites that are known to be exposed on the MNT molecule at mildly acidic $\mathrm{pH}$. Using the standardized set of labeling conditions outlined in the "Materials and methods" section, the ${ }^{111}$ In-NOTA-MNT labeling had moderately fast reaction kinetics at $37^{\circ} \mathrm{C}$ (Figure 2A). Yields for labeling these NOTA-MNT conjugates with ${ }^{111}$ In were relatively constant over a broad range of SDS concentration (Figure 2B), citrate concentration (Figure 2C), and pH (Figure 2D).

SDS-PAGE autoradiographs of the three ${ }^{111}$ In-NOTAMNT conjugates are presented in Figure 3A. Native PAGE of ${ }^{111}$ In-NOTA-MNT-EGF is presented in Figure S4. Initially, we used a standard commercial ${ }^{111}$ In preparation; however, this limited us to a maximal $0.2 \mathrm{GBq} / \mathrm{mg}$ specific activity for ${ }^{111}$ In-NOTA-MNT. It was possible to increase the 
A

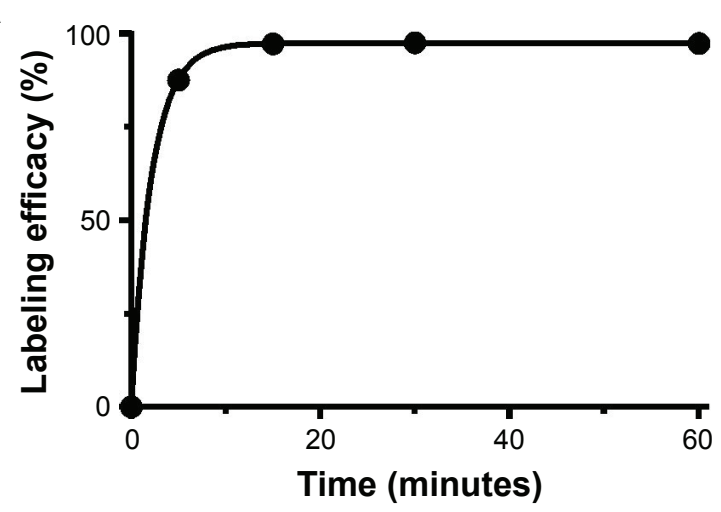

C

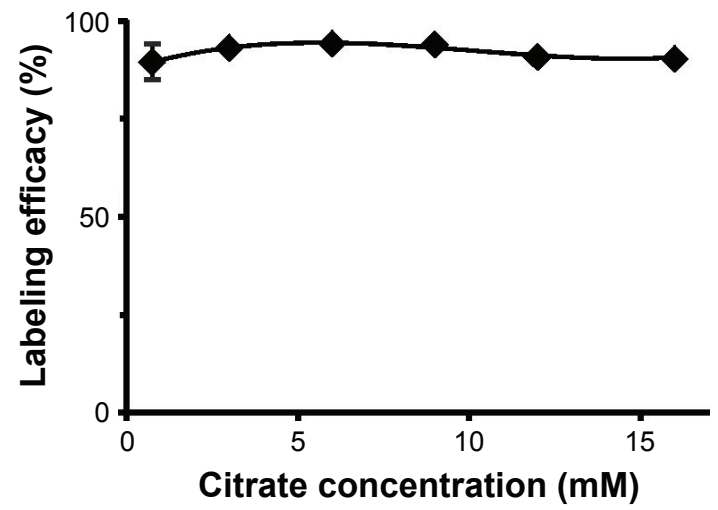

B

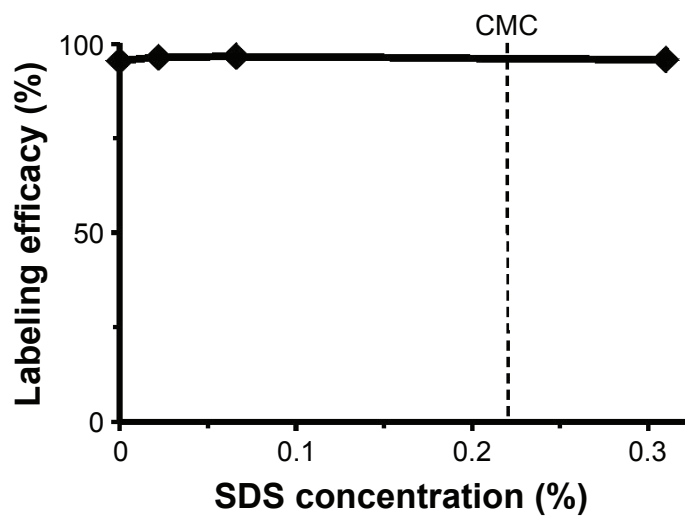

D

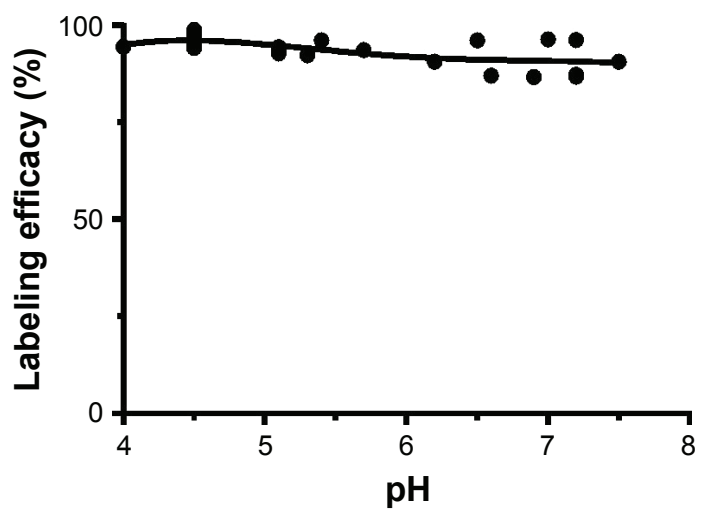

Figure 2 Labeling of NOTA-MNT-MSH with "'In as a function of: (A) reaction time, (B) SDS concentration in the reaction mixture, (C) citrate concentration, and (D) reaction mixture $\mathrm{pH}$.

Abbreviations: CMC, critical micelle concentration; MNT, modular nanotransporter; MSH, $\alpha$-melanocyte-stimulation hormone; SDS, sodium dodecyl sulfate.

${ }^{111}$ In-NOTA-MNT specific activity to a maximal value of 2.7 GBq/mg using custom-made batches of ${ }^{111}$ In (Figure 3B). Because labeling yields were consistently nearly quantitative $(96.5 \% \pm 0.1 \%, n=19)$, the ${ }^{111}$ In-NOTA-MNT were not purified before use. The same labeling process performed with conventionally used DOTA-MNT demonstrated rather slow reaction kinetics at $37^{\circ} \mathrm{C}$, reaching a plateau at approximately $3.5 \mathrm{~h}$ (Figure S5), limiting its further potential clinical translation; thus, all the studies were performed on NOTA-MNT.

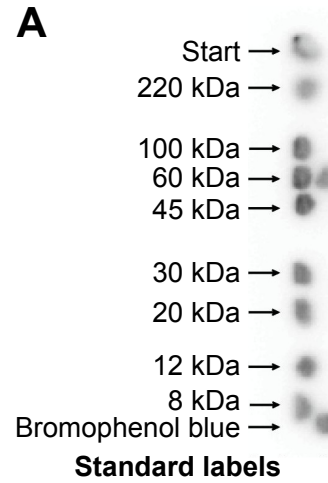

B

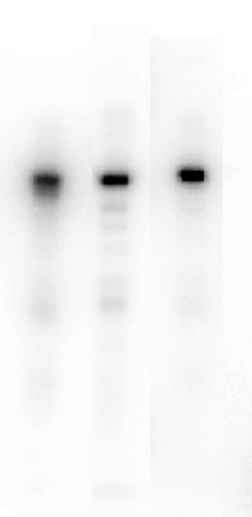

1
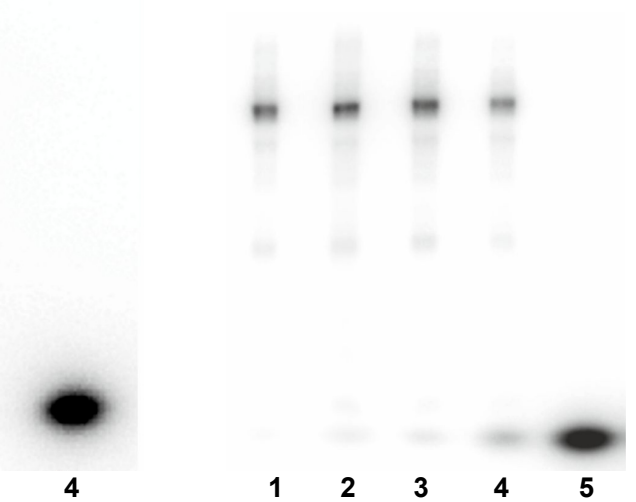

Figure 3 (A) Autoradiography of SDS-PAGE gels of '"'In-NOTA-MNT-MSH (lane I), "'In-NOTA-MNT-FA (lane 2), '"'In-NOTA-MNT-EGF (lane 3), and control "''In (lane 4). "Standard labels" indicate the bands from the ColorBurst ${ }^{\mathrm{TM}}$ Electrophoresis Markers. Prominent main band corresponds to the expected molecular weight for these constructs (70-76 kDa); negligible bands migrating directly ahead of bromophenol blue (compared to lane 4) correspond to free I''In (3\%-5\%). The faint bands ( $1 \%-10 \%)$, corresponding to an $\mathrm{M}_{\mathrm{w}}$ of $20-50 \mathrm{kDa}$, are MNT-NOTA protein degradation products that were eventually labeled. (B) Autoradiography of SDS-PAGE gels of "'In-NOTAMNT-MSH at different "'In/MNT ratios in the reaction mixture: 0.2 GBq/mg (lane I), I.I GBq/mg (lane 2), 2.0 GBq/mg (lane 3), 4.4 GBq/mg (lane 4), $7.3 \mathrm{GBq} / \mathrm{mg}$ (lane 5). Abbreviations: EGF, epidermal growth factor; FA, folic acid; MNT, modular nanotransporter; MSH, $\alpha$-melanocyte-stimulation hormone; SDS, sodium dodecyl sulfate. 


\section{Cytotoxicity studies}

The cytotoxicity of ${ }^{111}$ In-NOTA-MNTs compared to control

${ }^{111} \mathrm{InCl}_{3}$ was enhanced significantly and as would be expected for saturable, receptor-mediated targeting, the cytotoxic potency for these ${ }^{111} \mathrm{In}$-NOTA-MNT constructs was dependent on the specific activity of the labeled MNT. For example, significantly more efficient colony formation inhibition after ${ }^{111}$ In-NOTA-MNT-EGF treatment was observed at 2.7 $\mathrm{GBq} / \mathrm{mg}\left(\mathrm{A}_{10}\right.$, activity to give $10 \%$ survival $\left.=0.13 \mathrm{MBq} / \mathrm{mL}\right)$ compared with $0.2 \mathrm{GBq} / \mathrm{mg}\left(\mathrm{A}_{10}=0.38 \mathrm{MBq} / \mathrm{mL}\right.$; Figure 4). When ${ }^{11}$ In was delivered by MNT-FA to FR-positive cancer cells (HeLa, SK-OV-3), their ability to form colonies was reduced significantly, compared with nontargeted ${ }^{111} \mathrm{InCl}_{3}$ (Figure 5A and B). Moreover, this effect was abrogated when an excess of free FA was added to the cells, confirming the specificity of ${ }^{111} \mathrm{In}$-NOTA-MNT-FA cytotoxicity on FR-positive target cells (Figure 5A). Similar cytotoxic effects were observed for ${ }^{111}$ In delivered by MNT-MSH (Figure 5C) and MNT-EGF (Figure 5D) to the cancer cells overexpressing MC1R (B16-F1) or EGFR (U87.wtEGFR), respectively. Both these EGFR-targeted and MC1R-targeted MNTs have been previously demonstrated to act specifically on the target cells overexpressing EGFR or MC1R receptors, respectively. ${ }^{13,18}$ Manifold advantage of full-size MNT over MNTs lacking any of the functional domains for delivery of cytotoxic drug has been demonstrated previously. ${ }^{18}$

\section{Animal studies} SPECT/CT imaging

Following i.t. injection, ${ }^{111}$ In-NOTA-MNT-MSH demonstrated good intratumoral retention of ${ }^{111}$ In activity (Figure 6).

\section{A}

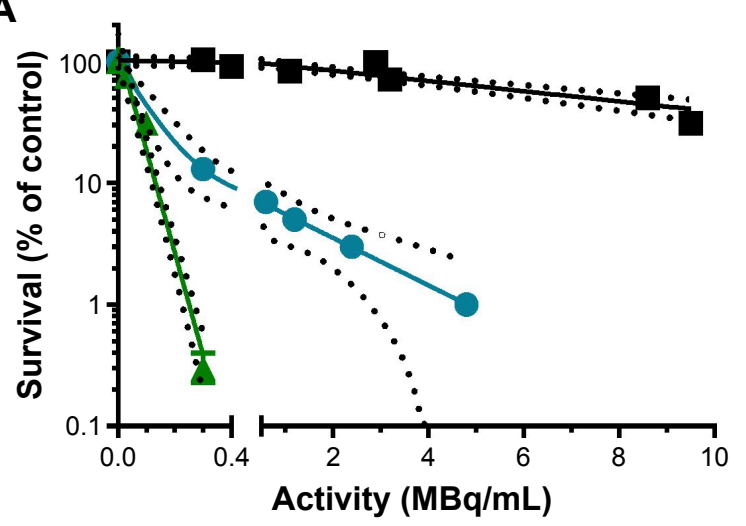

When fit to a single exponential equation, the decay-corrected clearance half-life from the B16-F1 tumor was calculated to be 3.7 days ( $95 \%$ confidence interval: $2.8-5.3$ ); however, the data were better $(P=0.0003, F$-test $)$ fit to a two-exponential equation with half-lives of about 0.5 and 11 days. Animated three-dimensional tomograms are presented in Video S1. Detection of radioactivity following intratumoral administration of ${ }^{111}$ In-NOTA-MNT-MSH in normal tissues was quite low and limited to nearly undetectable signal observed only in kidneys and liver (Figure 6).

\section{Therapy studies}

The potential utility of ${ }^{111}$ In-NOTA-MNT-MSH as a strategy for molecularly targeted radiotherapy was investigated after intratumoral injection in mice with subcutaneous B16-F1 melanoma tumors. Dose-dependent tumor growth delay was observed in three experiments $(2.6,5.2$, and $10.4 \mathrm{MBq}$, respectively) with ${ }^{111}$ In-NOTA-MNT-MSH (Figure 7). The highest dose was the most efficient resulting in $82 \%$ tumor growth inhibition, compared to control animals receiving saline. The corresponding dosages of either control ${ }^{111}$ In or nonlabeled NOTA-MNT-MSH did not result in any tumor growth inhibition.

\section{Discussion}

The main advantage of using Auger electrons for cancer treatment - the strong local damage of DNA - can be best achieved when the radionuclide is transported into the nuclei of cancer cells, but not into neighboring normal cells. Like many targeted radiotherapeutics, MNTs utilize receptor recognition to impart cancer cell specificity and internalization;

B

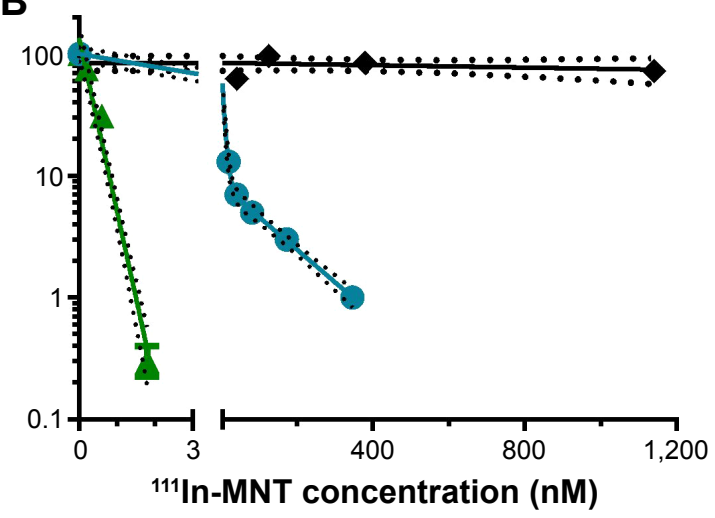

Figure 4 Cytotoxicity of "'In-NOTA-MNT-EGF on A43I cells with either high (2.7 GBq/mg) or low (0.2 GBq/mg) SA, unlabeled NOTA-MNT-EGF, and "'In control as a function of (A) radioactivity or (B) MNT concentration in the media. The solid lines represent a fit of the data to a mono-exponential ("'In, high SA "''In-NOTA-MNT-EGF) or a bi-exponential model ("'In-low SA NOTA-MNT-EGF).

Note: Dashed lines indicate $95 \%$ confidence intervals.

Abbreviations: EGF, epidermal growth factor; MNT, modular nanotransporter; SA, specific acivity. 


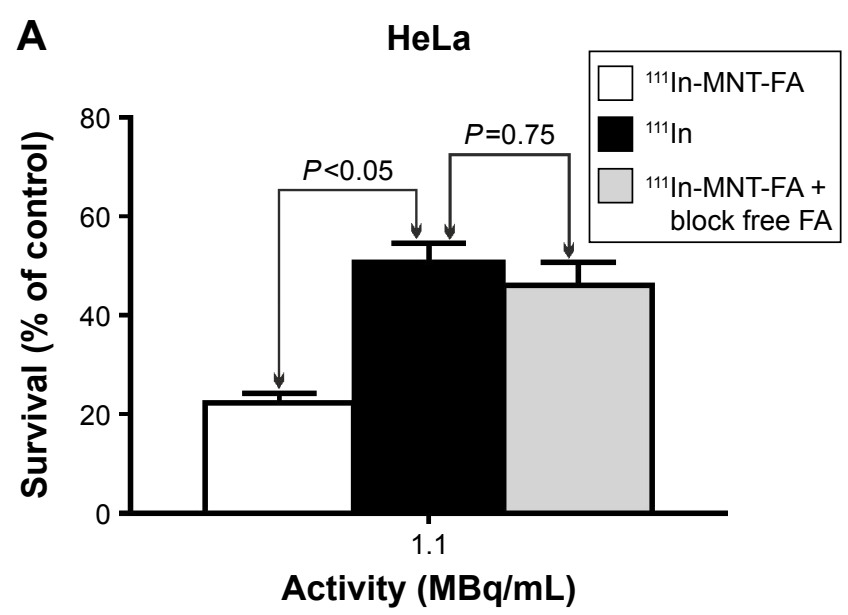

B SK-OV-3

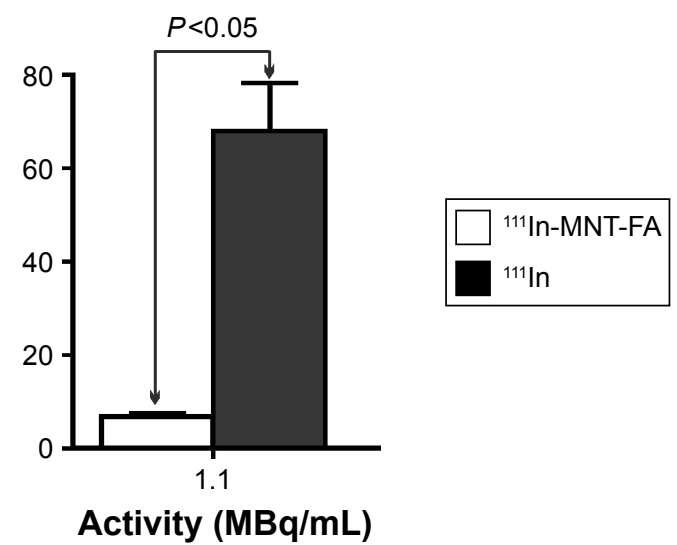

D

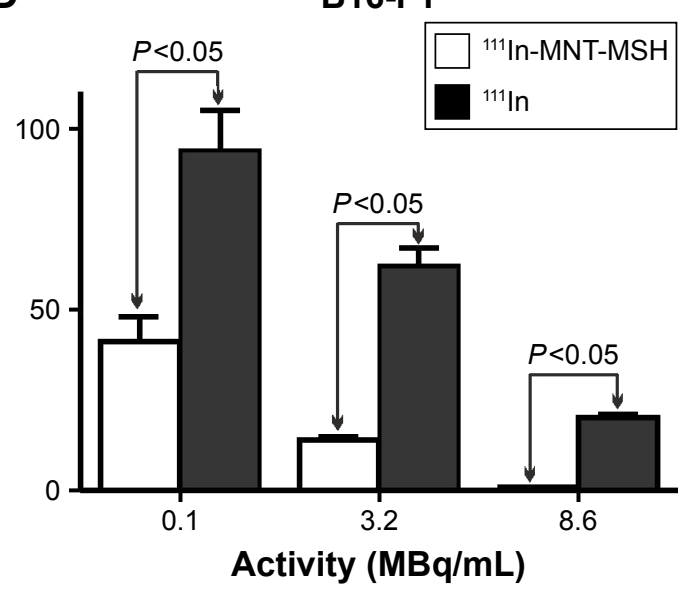

Figure 5 Cytotoxicity of: "'In-NOTA-MNT-FA on FR-positive (A) HeLa and (B) SK-OV-3; (C) "'In-NOTA-MNT-EGF on EGFR-positive U87MG.wtEGFR cells; and (D) '"'In-NOTA-MNT-MSH on MCIR-positive BI6-FI cells, all compared to "'In control and also FA-blocked "''In-NOTA-MNT-FA for HeLa cells.

Note: The significance of the difference was calculated using Kruskal-Wallis test.

Abbreviations: EGFR, epidermal growth factor receptor; FA, folic acid; FR, folate receptor; MCIR, melanocortin receptor-I; MNT, modular nanotransporter; $\mathrm{MSH}, \alpha$-melanocyte-stimulation hormone.

however, these events lead to translocation to endosomes rather than the cell nucleus. ${ }^{30,31}$ Because nuclear import machinery resides in the cytoplasm, the MNT must escape the endosomes before its NLS component can activate nuclear transport. This is accomplished by its endosomolytic module, which increases its hydrophobicity to provide penetration through the endosomal membrane in response to the decreased $\mathrm{pH}$ of acidifying endosomes. ${ }^{26}$ The ability of MNTs to escape from acidifying endosomes as well as the necessity of tDTox inclusion into MNT molecule have been demonstrated by us previously, ${ }^{26}$ along with their ability to accumulate efficiently in the nuclei of target cancer cells in vitro ${ }^{13,16,17}$ and in vivo. ${ }^{14}$ Unfortunately, this property of endosomolytic module is problematic from the perspective of ${ }^{111}$ In labeling because it makes the MNTs prone to aggregation in the $4-6.5 \mathrm{pH}$ range that is typically used for efficient ${ }^{111}$ In labeling. ${ }^{32,33}$ However, thorough optimization of the reaction conditions yielded $>96 \%$ labeling of all three NOTA-MNT conjugates, obviating the need for further purification, and at sufficient specific activity of $2.7 \mathrm{GBq} / \mathrm{mg}(222 \mathrm{GBq} / \mu \mathrm{mol})$. This ${ }^{111} \mathrm{In}$ labeling approach should be adaptable to other nanomedicines with biophysical characteristics incompatible with standard ${ }^{111}$ In protein labeling procedures.

Specific activity has been shown to be important for maximizing the therapeutic potential of a radiolabeled molecule even when labeled with $\alpha$-emitters that only require $<10$ atoms bound per cell to achieve effective cell kill. ${ }^{34}$ Because the number of Auger electron emitters needed to accomplish a similar degree of cytotoxicity is two to three orders of magnitude higher, ${ }^{16,17}$ maximizing the specific activity is a critical parameter for Auger emitter radiotherapy. Indeed, our studies with ${ }^{111}$ In-NOTA-MNT-EGF (Figure 4) demonstrated a profound increase in cytotoxicity when its specific activity was increased from 0.2 to $2.7 \mathrm{GBq} / \mathrm{mg}$, 

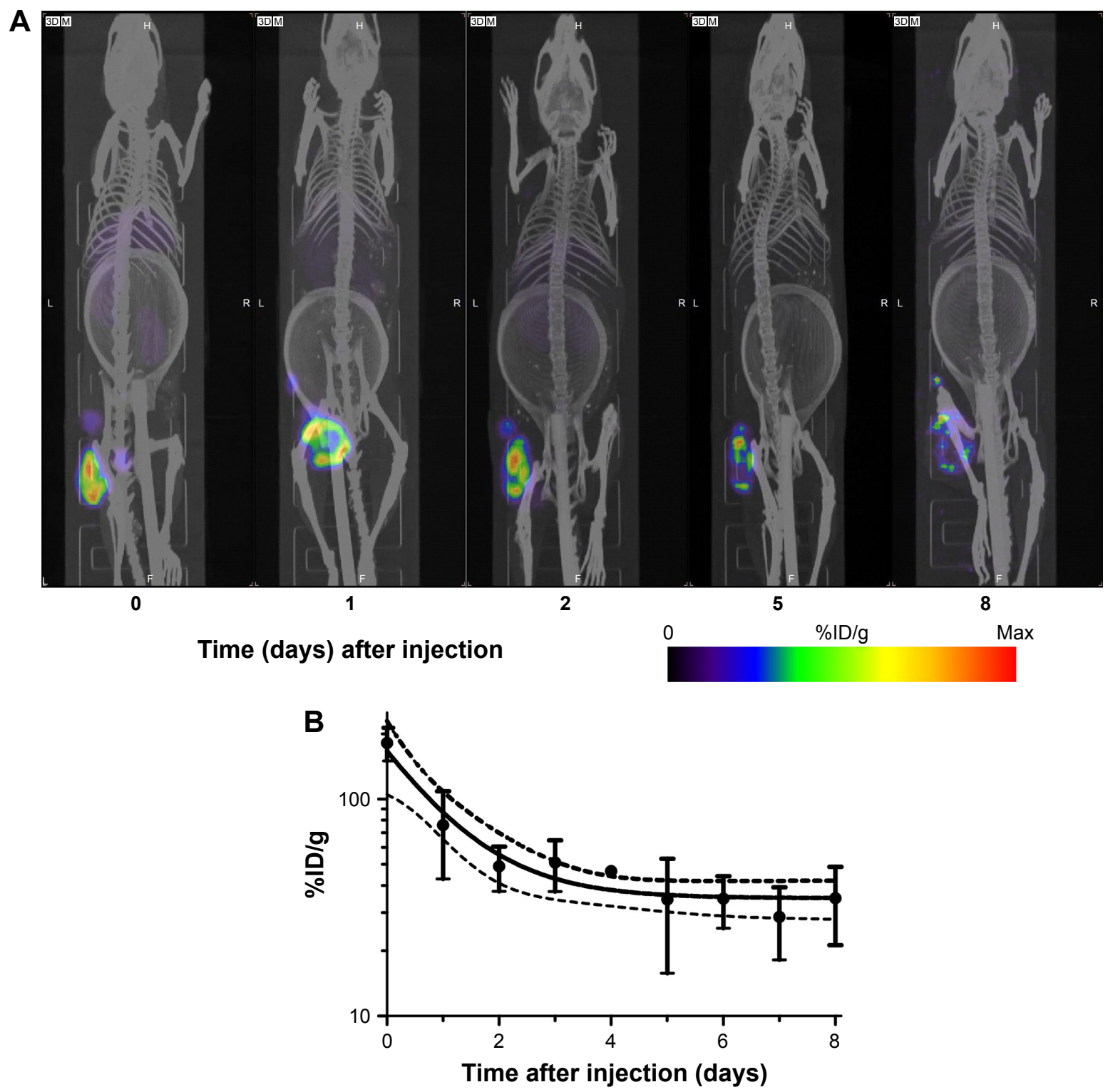

Figure 6 Serial SPECT/CT imaging of C57 black mice bearing BI6-FI melanoma tumors after intratumoral injection of "'In-NOTA-MNT-MSH.

Notes: (A) SPECT/CT (color/gray) images of representative animal at indicated times after injection; (B) decay-corrected clearance of "'IIn activity from the tumor. Dashed lines indicate $95 \%$ confidence interval. The ring in the abdominal region presented on the CT scans of the mice is the breathing sensor.

Abbreviations: MNT, modular nanotransporter; MSH, $\alpha$-melanocyte-stimulation hormone; SPECT/CT, single-photon emission computed tomography/computed tomography.

where about $12 \%$ of MNT was labeled. Beyond decreasing MNT mass and increasing ${ }^{111}$ In activity, if higher specific activity for these MNTs is required, it might be possible to modify the MNTs with a metal chelating polymer, which permitted site-specific addition of 24 or 29 DTPA groups to trastuzumab. ${ }^{35}$ Although this strategy was very effective in increasing the specific activity, this modification compromised NLS functionality and its effect on the in vivo behavior of the ${ }^{111}$ In-trastuzumab conjugate might be problematic.

With regard to the in vivo studies of molecularly targeted Auger electron radiotherapeutics, the current study is one of the few studies evaluating therapeutic efficacy.
Kassis ${ }^{5}$ utilized 5-[ $\left.{ }^{125} \mathrm{I}\right]$ iodo- $2^{\prime}$-deoxyuridine in a variety of animal models, generally by loco-regional administration, and with multiple doses of the therapeutic. Recently, Kiess et $\mathrm{al}^{10}$ reported significant growth delay of prostate-specific membrane antigen + PC3 PIP tumors after intravenous injection of ${ }^{125} \mathrm{I}-\mathrm{DCIBzL}$, a small prostate-specific membrane antigen-avid molecule. The therapeutic efficacy of several ${ }^{111}$ In-labeled monoclonal antibodies including those targeting HER29 and CD7436 has been evaluated, with encouraging responses observed in some cases. ${ }^{9,36}$ Potentially germane to the current studies with ${ }^{111}$ In-NOTA-MNT$\mathrm{EGF}$, Chen et $\mathrm{al}^{37}$ reported significant growth inhibition of 

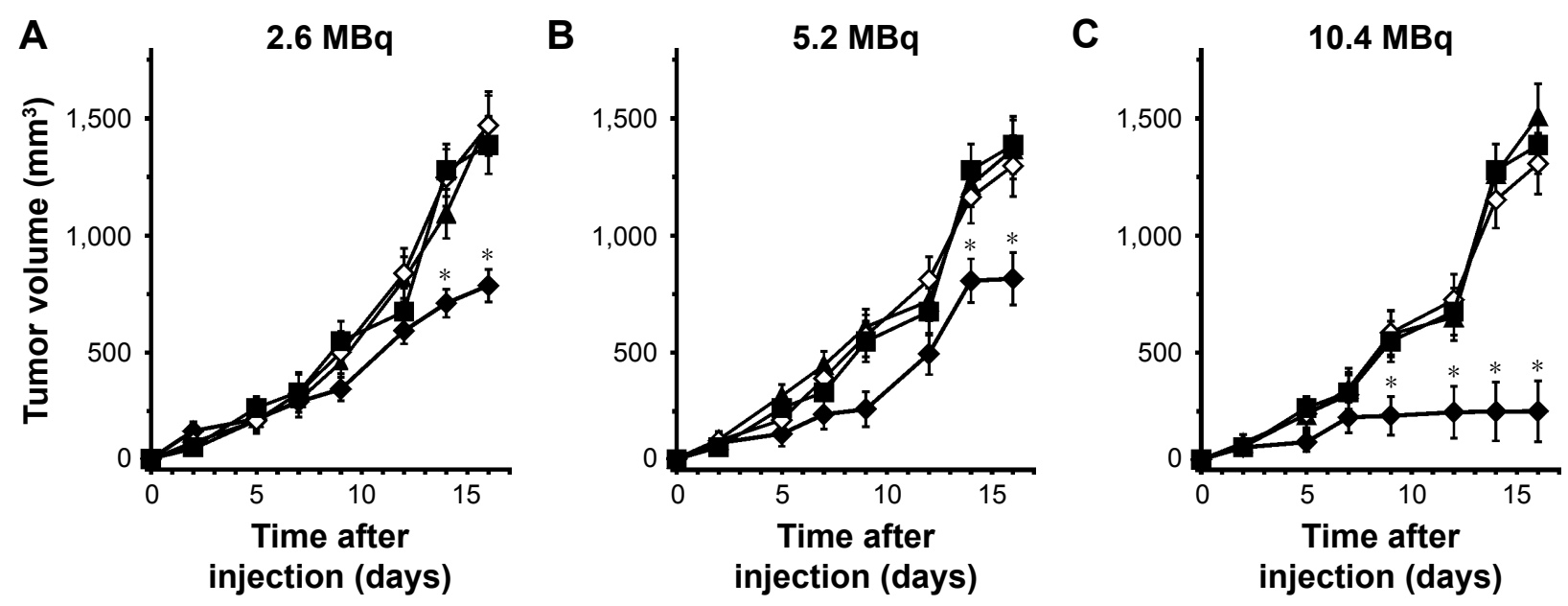

Figure 7 In vivo therapy of BI6-FI melanoma-bearing mice with "''In-NOTA-MNT-MSH ( $)$, using (A) $2.6,(\mathbf{B})$ 5.2, and (C) I0.4 MBq/mice, ${ }^{\prime \prime \prime} I n$ with the same activity ( $\left.\mathbf{A}\right)$, NOTA-MNT-MSH with the same concentration $(\diamond)$, or saline $(\square)$.

Note: $* P<0.05$ compared to control groups, according to the one-way ANOVA test.

Abbreviations: ANOVA, analysis of variance; MNT, modular nanotransporter; MSH, $\alpha$-melanocyte-stimulation hormone.

$10-15 \mathrm{~mm}^{3}$ subcutaneous human breast carcinoma xenografts after they received five weekly doses of ${ }^{111}$ In-DTPA-EGF at a cumulative dose of $92.5 \mathrm{MBq}$. Direct comparisons were not made between an ${ }^{111} \mathrm{In}$-EGF and an ${ }^{111} \mathrm{In}$-MNT-EGF construct in the present article; however, we do note that in a previous study using residualizing ${ }^{125} \mathrm{I}$ labeling, the in vitro cytotoxicity of [ $\left.{ }^{125} \mathrm{I}\right] \mathrm{SGMIB-MNT-EGF}$ was 5-18 times higher than that of $\left[{ }^{125} \mathrm{I}\right] \mathrm{SGMIB-EGF} .{ }^{16}$

For in vivo proof-of-principle experiments, we selected MNT-MSH, targeted to melanoma cells, which overexpress MC1R. ${ }^{38}$ This MNT has been regarded recently as a promising approach for the treatment of malignant melanoma, ${ }^{39-41}$ including uveal melanoma. ${ }^{42}$ Although skin melanomas are usually managed by surgical excision, ocular melanomas are routinely treated with brachytherapy. ${ }^{43,44}$ While effective $\gamma$-emitting $\left({ }^{125} \mathrm{I},{ }^{103} \mathrm{Pd}\right)$ or $\beta$-emitting $\left({ }^{106} \mathrm{Ru}\right)$ eye plaques are utilized for brachytherapy, this treatment can lead to nonspecific damage of healthy eye tissues. ${ }^{44,45}{ }^{111}$ In-NOTAMNT-MSH might have an advantage over conventional brachytherapy in this setting due to its specific action on MC1R-expressing melanoma cells.

As a first step, the tissue distribution and therapeutic efficacy of ${ }^{111} \mathrm{In}-\mathrm{NOTA}-\mathrm{MNT}-\mathrm{MSH}$ was evaluated after loco-regional administration in the mouse melanoma B16-F1 subcutaneous tumor model. SPECT imaging revealed prolonged retention of ${ }^{111} \mathrm{In}$ in the tumor and minimal activity in normal tissues. Although catabolite analyses were not performed, the lack of normal tissue activity suggests that ${ }^{111}$ In escaped from the tumor either as, or was rapidly converted to, a rapidly excreted form. Moreover, the results from single-dose ${ }^{111}$ In-NOTA-MNT-MSH tumor growth delay experiments were promising and compared favorably to those obtained with other Auger electron emitting therapeutics. Based on studies with other Auger emitting therapeutics such as ${ }^{111}$ In-DTPA-EGF ${ }^{37}$ as well as our own with MNT-MSH photosensitizer conjugates, ${ }^{14,18}$ it should be possible to further enhance therapeutic efficacy through the use of multidose ${ }^{111}$ In-NOTA-MNT-MSH strategies, and studies are planned to investigate this possibility.

\section{Conclusion}

Using an ${ }^{111}$ In labeling procedure modified for compatibility with MNT biophysical properties, MNTs targeting EGFR, FR, and MC1R were labeled in excellent yield providing suitable specific activity for the efficient treatment. The resultant ${ }^{111}$ In-NOTA-MNT conjugates were shown to be highly cytotoxic against cancer cells overexpressing these receptors, and one of these, ${ }^{111}$ In-NOTA-MNT-MSH, exhibited encouraging therapeutic potential in a murine model of melanoma. Taken together, these results suggest that MNTs warrant further evaluation as a platform technology for ${ }^{111}$ In Auger electron molecular radiotherapy with the vehicles for targeted intracellular delivery into the nuclei of cancer cells.

\section{Acknowledgments}

This work was supported in part (the development of labeling of NOTA-MNTs with ${ }^{111} \mathrm{In}$, and all experiments performed on ${ }^{111}$ In-NOTA-MNT-FA) by the Russian Science Foundation Grant 14-14-00874. The rest of this work was supported by the State Assignment Grant 0100-2014-0013 and the State Contract 13411.1008799.13.135. We thank YV Khramtsov for the excellent help with atomic force microscopy experiments. 
We thank YuR Sharapova, DP Sianova, and AS Abrosimov for the excellent technical assistance. Experiments were carried out with the use of the equipment from MV Lomonosov Moscow State University Program of Development and the Center of Collective Usage of the Institute of Gene Biology.

\section{Author contributions}

TAS, AAR, and ASS designed and evaluated the study. RIY and NBM designed and evaluated the therapeutic experiment with mice. TAS, AAR, NBM, MSV, VMP, TNL, AVU, and RIY performed the study and data analysis. TAS, AAR, MRZ, and ASS wrote the manuscript. All authors contributed toward data analysis, drafting and critically revising the paper and agree to be accountable for all aspects of the work. All authors read and approved the final manuscript.

\section{Disclosure}

The authors report no conflicts of interest in this work.

\section{References}

1. Rajendran L, Knolker HJ, Simons K. Subcellular targeting strategies for drug design and delivery. Nat Rev Drug Discov. 2010;9(1):29-42.

2. Li Y, Wang J, Wientjes MG, Au JL. Delivery of nanomedicines to extracellular and intracellular compartments of a solid tumor. Adv Drug Deliv Rev. 2012;64(1):29-39.

3. Wei H, Zhuo RX, Zhang XZ. Design and development of polymeric micelles with cleavable links for intracellular drug delivery. Progr Polymer Sci. 2013;38:503-535.

4. Tammam SN, Azzazy HM, Lamprecht A. How successful is nuclear targeting by nanocarriers? J Control Release. 2016;229:140-153.

5. Kassis AI. The amazing world of auger electrons. Int J Radiat Biol. 2004;80(11-12):789-803.

6. Buchegger F, Perillo-Adamer F, Dupertuis YM, Delaloye AB. Auger radiation targeted into DNA: a therapy perspective. Eur J Nucl Med Mol Imaging. 2006;33(11):1352-1363.

7. Cornelissen B, Vallis KA. Targeting the nucleus: an overview of Augerelectron radionuclide therapy. Curr Drug Discov Technol. 2010;7(4): 263-279.

8. Costantini DL, Chan C, Cai Z, Vallis KA, Reilly RM. ${ }^{111}$ In-labeled trastuzumab (Herceptin) modified with nuclear localization sequences (NLS): an Auger electron-emitting radiotherapeutic agent for HER2/ neu-amplified breast cancer. $J$ Nucl Med. 2007;48(8):1357-1368.

9. Costantini DL, McLarty K, Lee H, Done SJ, Vallis KA, Reilly RM. Antitumor effects and normal-tissue toxicity of ${ }^{111} \mathrm{In}$-nuclear localization sequence-trastuzumab in athymic mice bearing HER-positive human breast cancer xenografts. J Nucl Med. 2010;51(7):1084-1091.

10. Kiess AP, Minn I, Chen Y, et al. Auger radiopharmaceutical therapy targeting prostate-specific membrane antigen. J Nucl Med. 2015;56(9): 1401-1407.

11. Hoang B, Reilly RM, Allen C. Block copolymer micelles target auger electron radiotherapy to the nucleus of HER2-positive breast cancer cells. Biomacromolecules. 2012;13(2):455-465.

12. Panosa C, Fonge H, Ferrer-Batalle M, et al. A comparison of non-biologically active truncated EGF (EGFt) and full-length hEGF for delivery of Auger electron-emitting ${ }^{111}$ In to EGFR-positive breast cancer cells and tumor xenografts in athymic mice. Nucl Med Biol. 2015;42(12):931-938.

13. Gilyazova DG, Rosenkranz AA, Gulak PV, et al. Targeting cancer cells by novel engineered modular transporters. Cancer Res. 2006;66(21): 10534-10540.
14. Slastnikova TA, Rosenkranz AA, Gulak PV, et al. Modular nanotransporters: a multipurpose in vivo working platform for targeted drug delivery. Int J Nanomedicine. 2012;7:467-482.

15. Rosenkranz AA, Vaidyanathan G, Pozzi OR, Lunin VG, Zalutsky MR, Sobolev AS. Engineered modular recombinant transporters: application of new platform for targeted radiotherapeutic agents to alpha-particle emitting ${ }^{211}$ At. Int J Radiat Oncol Biol Phys. 2008;72(1):193-200.

16. Slastnikova TA, Koumarianou E, Rosenkranz AA, et al. Modular nanotransporters: a versatile approach for enhancing nuclear delivery and cytotoxicity of Auger electron-emitting ${ }^{125}$ I. EJNMMI Res. 2012; 2(1):59.

17. Koumarianou E, Slastnikova TA, Pruszynski M, et al. Radiolabeling and in vitro evaluation of ${ }^{67} \mathrm{Ga}$-NOTA-modular nanotransporter: potential Auger electron emitting EGFR-targeted radiotherapeutic. Nucl Med Biol. 2014;41(6):441-449.

18. Rosenkranz AA, Lunin VG, Gulak PV, et al. Recombinant modular transporters for cell-specific nuclear delivery of locally acting drugs enhance photosensitizer activity. FASEB J. 2003;17(9):1121-1123.

19. Howell RW. Radiation spectra for Auger-electron emitting radionuclides: report No 2 of AAPM Nuclear Medicine Task Group No 6 . Med Phys. 1992;19(6):1371-1383.

20. Goddu SM, Howell RW, Bouchet LG, Bolch WE, Rao DV. MIRD Cellular S Values. Reston, VA: Society of Nuclear Medicine; 1997.

21. Leamon CP, Low PS. Delivery of macromolecules into living cells: a method that exploits folate receptor endocytosis. Proc Natl Acad Sci U S A. 1991;88(13):5572-5576.

22. Sun Y, Martell AE, Welch MJ. Synthesis of a new diaminodithiol bifunctional chelator for radiolabeling biomolecules with indium (III). Tetrahedron. 2000;56(29):5093-5103.

23. Solca F, Siegrist W, Drozdz R, Girard J, Eberle AN. The receptor for alpha-melanotropin of mouse and human melanoma cells. Application of a potent alpha-melanotropin photoaffinity label. J Biol Chem. 1989;264(24):14277-14281.

24. Paulos CM, Reddy JA, Leamon CP, Turk MJ, Low PS. Ligand binding and kinetics of folate receptor recycling in vivo: impact on receptormediated drug delivery. Mol Pharmacol. 2004;66(6):1406-1414.

25. Siu MK, Kong DS, Chan HY, et al. Paradoxical impact of two folate receptors, FR+- and RFC, in ovarian cancer: effect on cell proliferation, invasion and clinical outcome. PLoS One. 2012;7(11):e47201.

26. Khramtsov YV, Rokitskaya TI, Rosenkranz AA, et al. Modular drug transporters with diphtheria toxin translocation domain form edged holes in lipid membranes. J Control Release. 2008;128(3):241-247.

27. Wadas TJ, Wong EH, Weisman GR, Anderson CJ. Coordinating radiometals of copper, gallium, indium, yttrium, and zirconium for PET and SPECT imaging of disease. Chem Rev. 2010;110(5): 2858-2902.

28. Brom M, Joosten L, Oyen WJ, Gotthardt M, Boerman OC. Improved labelling of DTPA-and DOTA-conjugated peptides and antibodies with ${ }^{111}$ In in HEPES and MES buffer. EJNMMI Res. 2012;2:4.

29. Morfin JF, Toth E. Kinetics of Ga (NOTA) formation from weak Ga-citrate complexes. Inorg Chem. 2011;50(20):10371-10378.

30. Rosenkranz AA, Ulasov AV, Slastnikova TA, Khramtsov YV, Sobolev AS. Use of intracellular transport processes for targeted drug delivery into a specified cellular compartment. Biochemistry (Mosc). 2014;79(9):928-946.

31. Sobolev AS. Modular transporters for subcellular cell-specific targeting of anti-tumor drugs. Bio Essays. 2008;30(3):278-287.

32. Price EW, Orvig C. Matching chelators to radiometals for radiopharmaceuticals. Chem Soc Rev. 2014;43(1):260-290.

33. Sosabowski JK, Mather SJ. Conjugation of DOTA-like chelating agents to peptides and radiolabeling with trivalent metallic isotopes. Nat Protoc. 2006;1(2):972-976.

34. Akabani G, Carlin S, Welsh P, Zalutsky MR. In vitro cytotoxicity of 211At-labeled trastuzumab in human breast cancer cell lines: effect of specific activity and HER2 receptor heterogeneity on survival fraction. Nucl Med Biol. 2006;33(3):333-347. 
35. Ngo Ndjock Mbong G, Lu Y, Chan C, et al. Trastuzumab labeled to high specific activity with 111 In by site-specific conjugation to a metalchelating polymer exhibits amplified auger electron-mediated cytotoxicity on HER2-positive breast cancer cells. Mol Pharm. 2015;12(6): 1951-1960.

36. Michel RB, Rosario AV, Andrews PM, Goldenberg DM, Mattes MJ. Therapy of small subcutaneous B-lymphoma xenografts with antibodies conjugated to radionuclides emitting low-energy electrons. Clin Cancer Res. 2005;11(2 Pt 1):777-786.

37. Chen P, Cameron R, Wang J, Vallis KA, Reilly RM. Antitumor effects and normal tissue toxicity of ${ }^{111}$ In-labeled epidermal growth factor administered to athymic mice bearing epidermal growth factor receptorpositive human breast cancer xenografts. J Nucl Med. 2003;44(9): 1469-1478.

38. Rosenkranz AA, Slastnikova TA, Durymanov MO, Sobolev AS. Malignant melanoma and melanocortin 1 receptor. Biochemistry (Mosc). 2013;78(11):1228-1237.

39. Simoes MC, Sousa JJ, Pais AA. Skin cancer and new treatment perspectives: a review. Cancer Lett. 2015;357(1):8-42.

40. Silva CO, Martinho N, Aniceto N, Reis CP. Melanoma prevention: challenges and progresses in nanotechnology for melanoma prevention and treatment. In: Kharisov BI, Kharissova OV, Ortiz-Mendez U, editors. CRC Concise Encyclopedia of Nanotechnology. Boca-Raton, London, New York: CRC Press; 2015:453-470.
41. Slastnikova TA, Rosenkranz AA, Lupanova TN, Gulak PV, Gnuchev NV, Sobolev AS. Study of efficiency of the modular nanotransporter for targeted delivery of photosensitizers to melanoma cell nuclei in vivo. Dokl Biochem Biophys. 2012;446(1):235-237.

42. You S, Luo J, Grossniklaus HE, Gou ML, Meng K, Zhang Q. Nanomedicine in the application of uveal melanoma. Int J Ophtalmol. 2016; 9(8):1215-1225.

43. Jiang P, Kanzia G, Neumann D, Roider J, Dunst J. ${ }^{106}$ Ruthenium eye plaque brachytherapy in the management of medium sized uveal melanoma. Int J Radiat Oncol Biol Phys. 2015;93:E77-E78.

44. Wisely CE, Hadziahmetovic M, Reem RE, et al. Long-term visual acuity outcomes in patients with uveal melanoma treated with ${ }^{125}$ I episcleral OSU-Nag plaque brachytherapy. Brachytherapy. 2016;15(1):12-22.

45. ABS-OOTF Committee. The American Brachytherapy Society consensus guidelines for plaque brachytherapy of uveal melanoma and retinoblastoma. Brachytherapy. 2014;13(1):1-14. 


\section{Supplementary materials}

Video SI SPECT visualization of "'In-labeled MCIR-targeted MNT retention in mice.
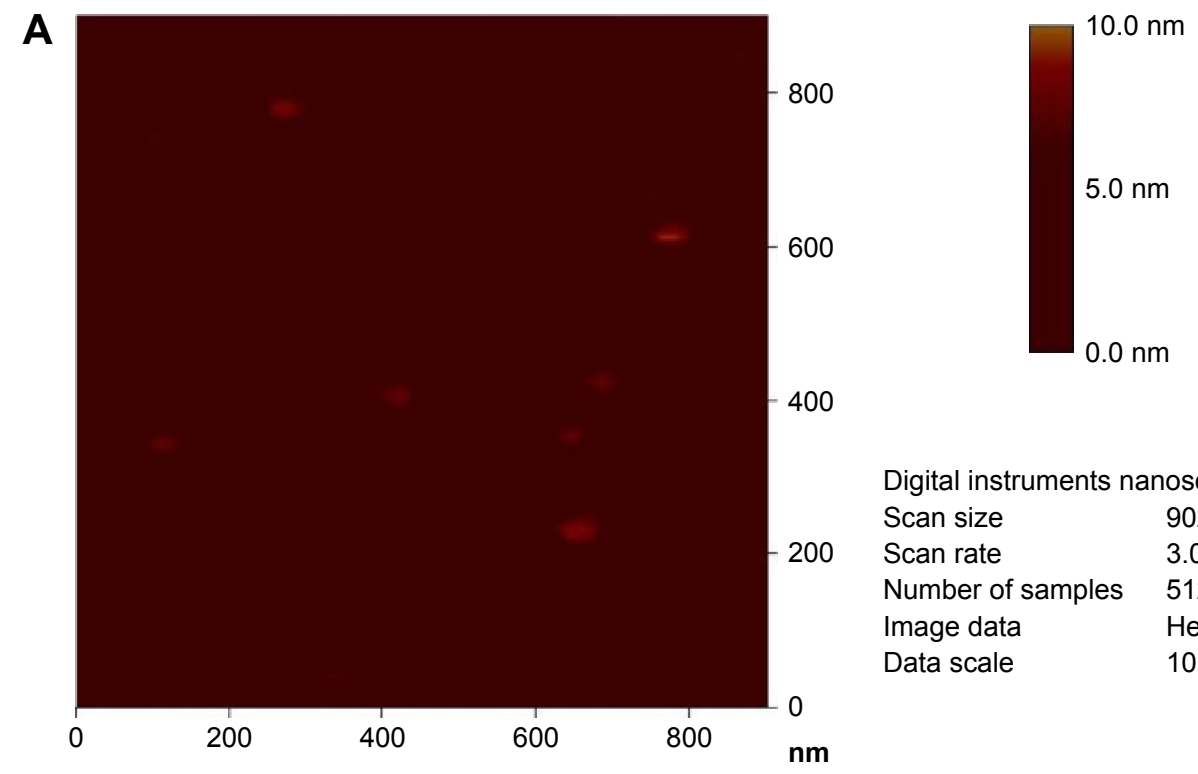

400

Digital instruments nanoscope Scan size $\quad 902.3 \mathrm{~nm}$

200 Scan rate $\quad 3.052 \mathrm{~Hz}$

Number of samples 512

Image data Height

Data scale $\quad 10.000 \mathrm{~nm}$
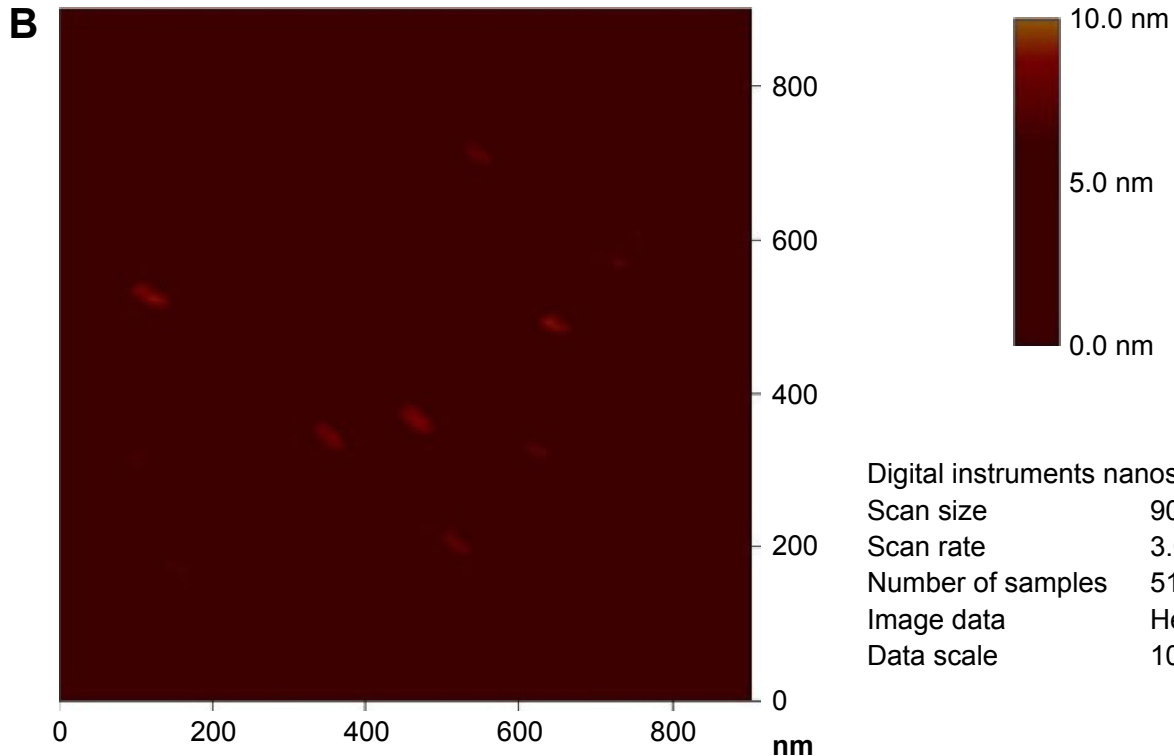

400

Digital instruments nanoscope

Scan size $\quad 902.3 \mathrm{~nm}$

200 Scan rate $\quad 3.052 \mathrm{~Hz}$

Number of samples 512

Image data Height

Data scale $\quad 10.000 \mathrm{~nm}$

Figure SI (Continued) 


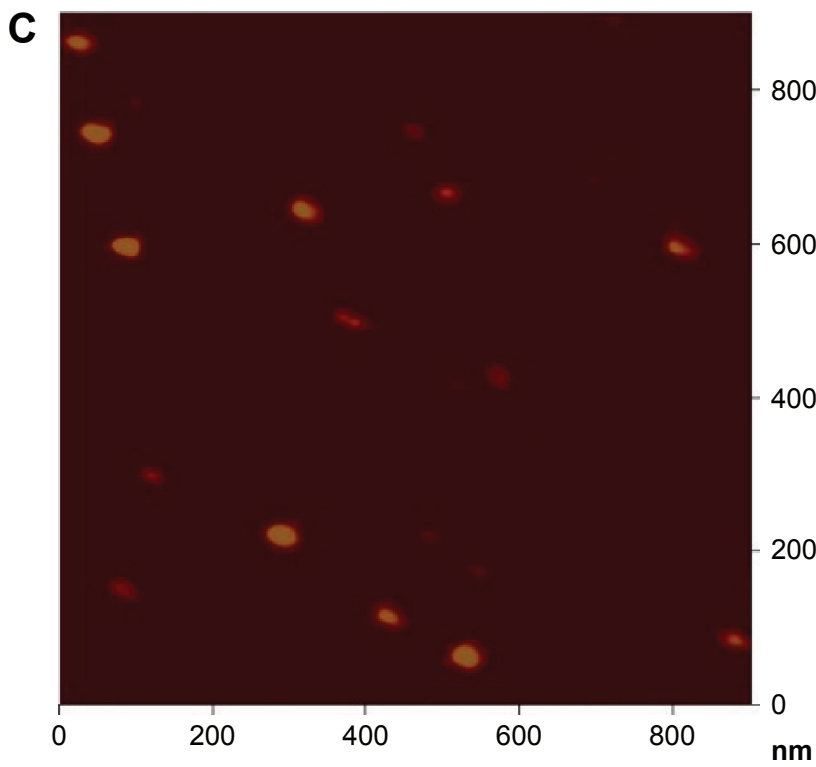

$10.0 \mathrm{~nm}$

800

600

Digital instruments nanoscope

Scan size $\quad 902.3 \mathrm{~nm}$

Scan rate

Number of samples 512

Image data Height

Data scale $\quad 10.000 \mathrm{~nm}$

Figure SI Typical images of (A) MNT-MSH, (B) MNT-EGF, and (C) MNT-FA obtained using atomic force microscopy scanning.

Notes: A Digital Instruments Multimode Scanning Probe Microscope on a Nanoscope Illa (Veeco Instruments, Woodbury, NY, USA) controller fitted with J-scanner ( $165 \mu \mathrm{m}$ maximum scan size) and a Tapping Mode Liquid Cell were used to image MNT molecule in situ. Freshly cleaved mica was incubated in 0.5\% methanol diluted 3-(trimethoxysilyl)propyl methacrylate (Fluka, Seelze, Germany) for $45 \mathrm{~min}$ and washed with methanol and water. Finally, the mica was incubated in $0.2 \%$ (weight) ammonium peroxodisulfate and $0.2 \%$ (volume) $N, N, N^{\prime}, N^{\prime}$-tetramethylethylenediamine (both from Fluka), and I $50 \mu \mathrm{L}$ of $0.2 \mathrm{nM}$ MNT solution for 45 min and washed with water and $50 \mathrm{mM}$ phosphate buffer at $\mathrm{pH}$ 8.0. All measurements were performed in $10 \mathrm{mM}$ sodium phosphate, $150 \mathrm{mM} \mathrm{NaCl}, \mathrm{pH} 8.0$, in a tapping mode at $\mathrm{RT}$ using a tip scan rate about $3 \mathrm{~Hz}$. All images were captured as $512 \times 5 \mathrm{I} 2$ pixels and were flattened and smoothed.

Abbreviations: EGF, epidermal growth factor; FA, folic acid; MNT, modular nanotransporter; MSH, $\alpha$-melanocyte-stimulation hormone; RT, room temperature.

A

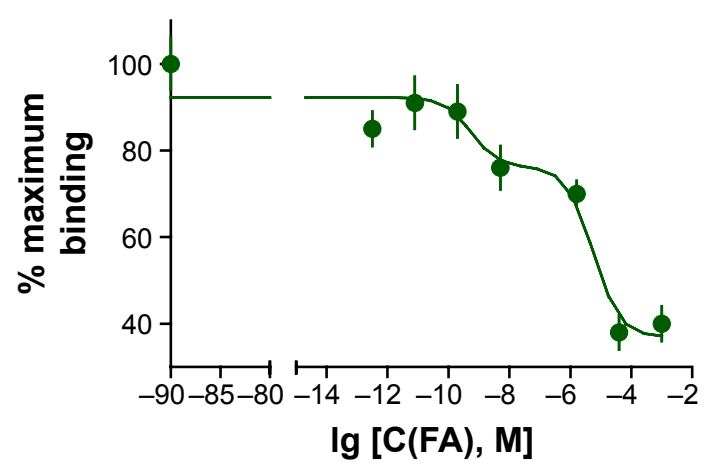

B

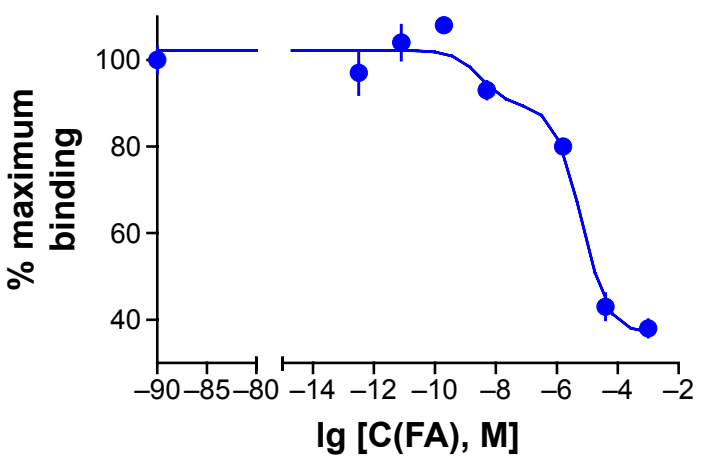

Figure S2 Binding of "''In-NOTA-MNT-FA to FR-expressing (A) HeLa and (B) SK-OV-3 cells.

Notes: Filled circles represent experimental data with SEM $(n=3)$ and the solid lines represent a fit of the data to a Two sites - Fit logIC50 model in GraphPad Prism 5. Competition experiments were carried out in 24-well plates with $3.7 \mathrm{nM}$ of "'In-NOTA-MNT-FA and incrementing concentrations of free FA in $300 \mu \mathrm{L}$ of folate-free media without bicarbonate supplemented with $20 \mathrm{mM} \mathrm{HEPES}$ and $20 \mathrm{mg} / \mathrm{mL} \mathrm{BSA}$, pH 7.3. The plates were incubated at $4^{\circ} \mathrm{C}$ for $20 \mathrm{~h}$, washed seven times with $500 \mu \mathrm{L}$ ice-cold Hanks solution containing BSA, then the cells were lysed with $0.5 \mathrm{M} \mathrm{NaOH}$, and the radioactivity in the cell lysates was measured with a gamma-counter.

Abbreviations: BSA, bovine serum albumin; FA, folic acid; FR, folate receptor; MNT, modular nanotransporter; SEM, standard error of the mean. 
A

$18 \mathrm{kDa}$

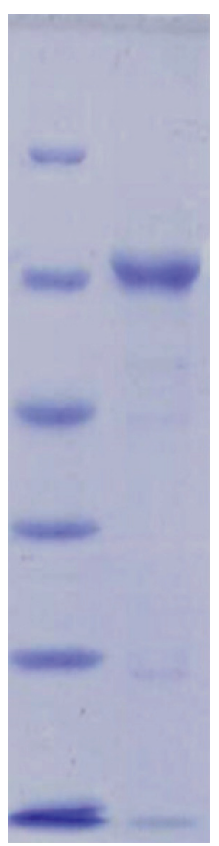

B

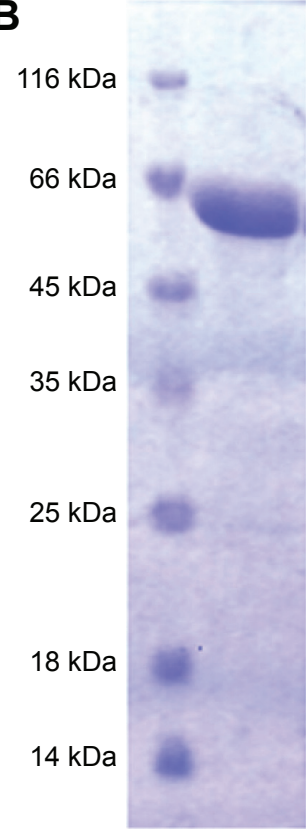

C

$116 \mathrm{kDa}$

$66 \mathrm{kDa}$

$45 \mathrm{kDa}$

$35 \mathrm{kDa}$

$25 \mathrm{kDa}$

$18 \mathrm{kDa}$

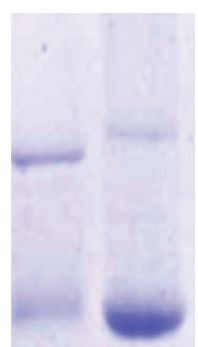

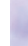
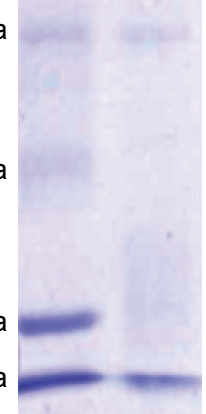

Figure S3 Coomassie blue protein staining of SDS-PAGE gel of (A) NOTA-MNT-MSH, (B) NOTA-MNT-EGF, (C) MNT-FA.

Note: Labels on the left indicate the bands of Thermo Scientific Unstained Protein Molecular Weight Marker 26610 (Thermo Fisher Scientific, Waltham, MA, USA).

Abbreviations: EGF, epidermal growth factor; FA, folic acid; MNT, modular nanotransporter; MSH, $\alpha$-melanocyte-stimulation hormone; SDS, sodium dodecyl sulfate.

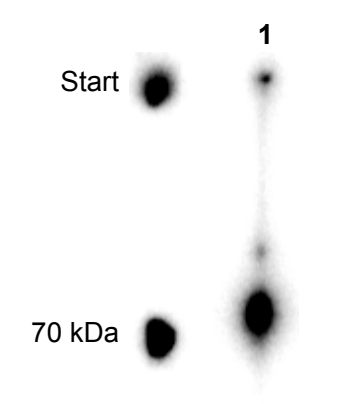

Bromophenol

blue

Figure S4 Autoradiography of native PAGE gel of "'In-NOTA-MNT-EGF (76 kDa).

Notes: Labels on the left indicate the start (top), the $70 \mathrm{kDa}$ marker (middle), and the bromophenol blue migration front (bottom). Prominent main band (approximately $82 \%$ ) corresponds to the expected molecular weight of "'In-NOTA-MNT (76 kDa), the faint band just above (5\%) corresponds to dimer, as the band at the start (I0\%) corresponds to somewhat more aggregated label product.

Abbreviations: EGF, epidermal growth factor; MNT, modular nanotransporter. 


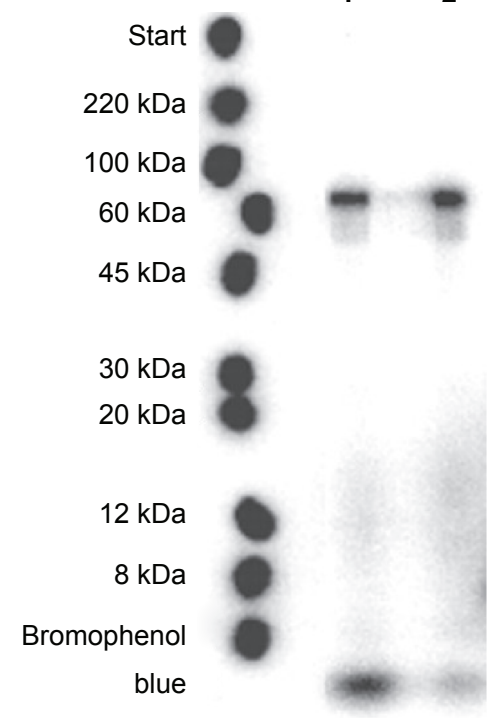

Figure S5 Completeness of the reaction of "'In labeling with DOTA-MNT-EGF.

Notes: Autoradiography of SDS-PAGE gels of '"In-DOTA-MNT-EGF after $2 \mathrm{~h}$ of reaction (lane I) or after $3 \mathrm{~h} 40 \mathrm{~min}$ (lane 2) at $37^{\circ} \mathrm{C}$. The band on the bottom of each lane corresponds to unreacted "'In. Labels on the left indicate the bands from the ColorBurst ${ }^{\mathrm{TM}}$ Electrophoresis Markers.

Abbreviations: EGF, epidermal growth factor; MNT, modular nanotransporter; SDS, sodium dodecyl sulfate.

\section{Publish your work in this journal}

The International Journal of Nanomedicine is an international, peerreviewed journal focusing on the application of nanotechnology in diagnostics, therapeutics, and drug delivery systems throughout the biomedical field. This journal is indexed on PubMed Central, MedLine, CAS, SciSearch ${ }^{\circledR}$, Current Contents ${ }^{\circledR} /$ Clinical Medicine,
Journal Citation Reports/Science Edition, EMBase, Scopus and the Elsevier Bibliographic databases. The manuscript management system is completely online and includes a very quick and fair peer-review system, which is all easy to use. Visit http://www.dovepress.com/ testimonials.php to read real quotes from published authors.

Submit your manuscript here: http://www.dovepress.com/international-journal-of-nanomedicine-journal 